\title{
Relevance of Ampk to Male Reproduction
}

\author{
Thi Mong Diep NGUYEN ${ }^{1,2}$ \\ ${ }^{1}$ Quy Nhon University, VietNam \\ ${ }^{2}$ INRA, Physiologie de la Reproduction et des Comportements, F-37380 Nouzilly, France
}

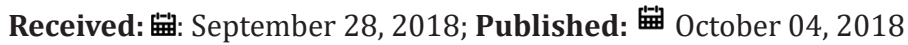

*Corresponding author: Thi Mong Diep NGUYEN, Quy Nhon University, 2INRA, Physiologie de la Reproduction et des Comportements, France

\section{Opinion}

Adenosine 5'-monophosphate activated protein kinase (AMPK) is a key enzymatic protein involved in linking the energy sensing to the many metabolic pathways and that has been recently shown to control male gonad and spermatozoa functions. It is indeed involved in the regulation of semen quality through its action on the proliferation of testicular somatic cells on spermatozoa motility and acrosome reaction. It also favors spermatozoa quality through the management of lipid peroxidation and antioxidant enzymes. AMPK is a heterotrimeric serine/threonine protein kinase consisting of one catalytic subunit $(\mathbb{\nabla})$ and two regulatory subunits $(\mathbb{}$ and $\bigotimes$ that exist as multiple isoforms and splice variants, resulting in the generation of twelve possible heterotrimeric combinations. The well-conserved genes encoding these subunits are found in the genomes of essentially all eukaryotes, including protists, fungi, plants, and animals. AMPK regulates metabolic energy balance at the whole-body level by responding to hormones and nutrient signals, which leads to changes in energy homeostasis [1].

Phosphorylation of a specific threonine residue (Thr172) of the $\alpha$-subunit is crucial for AMPK activity. Once activated by falling energy status, it promotes ATP production by increasing the activity or expression of proteins involved in catabolism (for example, glucose uptake, glycolysis, fatty acid oxidation and mitochondrial biogenesis). It does so while conserving ATP by switching off biosynthetic pathways such as the synthesis of fatty acids, triglyceride, cholesterol, glucose (via gluconeogenesis) or glycogen [2]. AMPK has been detected in male germinal cells in 2000 by Cheung et al. [3]. AMPK activity in male germinal cells was then presented in 2008 by Towler et al. [4]. The presence of AMPK, especially in its active form, phospho-AMPK-Thr172, was highlighted in different parts of sperm, depending on the species, like in the acrosome, the sub-equatorial segment of the head and in the intermediate part, the midpiece, and along the tail of the flagellum [5]. The localization of phospho-AMPK in sperm flagellum suggests that it acts through the phosphorylation of protein substrates involved in the functioning of the axoneme central apparatus that is essential for flagellar motility.

The mechanism was demonstrated for a testicular AMPKrelated kinase: TSSK2 (Testis-Specific Serine Kinase 2). TSKK2 phosphorylates SPAG16L, a protein of the axoneme central apparatus which is essential for spermatozoa flagellar motility [6-7]. Therefore, the AMPK distribution profile in spermatozoa cells suggests that it promotes in different ways both motility and acrosome reaction. The absence of AMPK $\alpha 1$ genes in testicular somatic cells has led to a $25 \%$ reduction in male fertility, associated with abnormal spermatozoa with a thin head, decreases spermatozoa production, as well as a reduction in mitochondrial membrane potential, a lower basal oxygen consumption, decreased testosterone secretion through a reduction in cholesterol transport into the mitochondria and decreased conversion of progesterone into androstenedione [8]. AMPK activation in spermatozoa influences motility, acrosome reaction and spermatozoa ability to successfully fertilize the oocyte.

AMPK is also implicated in the mitochondrial membrane potential, spermatozoa plasma membrane fluidity and organization, and acrosome integrity [5]. AMPK appears to be also involved in the mechanisms protecting the cells against toxic effects of ROS [9]. In cryopreserved semen, the activation of AMPK reduces ROS and LPO production and increases antioxydant activity [10]. Activation of AMPK could counteract the negative effects of oxidative stress by reducing superoxide anion, protein carbonyl, or NAFLD [11]. AMPK may increase the levels of intracellular NADPH in different ways: by the activation of the oxidation of fatty acids and by the inhibition of fatty acid synthesis to neutralize the cytotoxic ROS or through pentose phosphate pathway $[12,13]$.

\section{Conclusion}

It is seems likely that the appearance of the AMPK system was a very important event in the development of the male production. It 
is also involved in spermatozoa functions: in motility and acrosome reaction as well as in the energy and redox capacities in order to regulate cellular processes necessary for successful fertilization. Its role in the regulation of antioxidant defenses of the cell particularly affects the in vitro retention capacity, which is especially solicited during the freezing of semen. From a broader point of view, AMPK could become a therapeutic target for limiting infertility and improving biotechnologies of artificial insemination and semen conservation.

\section{References}

1. Hardie DG, Scott JW, Pan DA, Hudson ER (2003) Management of cellular energy by the AMP-activated protein kinase system. FEBS Lett 546: 113120.

2. Hardie DG, Ross FA, Hawley SA (2012) AMPK: A nutrient and energy sensor that maintains energy homeostasis. Nature Rev Mol Cell Biol 13: 251-262.

3. Cheung PC, Salt IP, Davies SP, Hardie D G, Carling D (2000) Characterization of AMP-activated protein kinase gamma-subunit isoforms and their role in AMP binding. Biochem J 346: 659-669.

4. Towler MC, Fogarty S, Hawley SA, Pan DA, Martin D, et al. (2008) A novel short splice variant of the tumour suppressor LKB1 is required for spermiogenesis. Biochem J 416: 1-14.

5. Nguyen TM (2017) Impact of 5'-amp-activated Protein Kinase on Male Gonad and Spermatozoa Functions. Front Cell Dev Biol 5: 25.

6. Scott JW, van Denderen BJ, Jorgensen SB, Honeyman JE, Steinberg GR, et al. (2008) Thienopyridone drugs are selective activators of AMPactivated protein kinase beta1-containing complexes. Chem Biol 15: 1220-1230.

7. Moreno D, Knecht E, Viollet B, Sanz P (2008) A-769662, a novel activator of AMP-activated protein kinase, inhibits non-proteolytic components of the $26 \mathrm{~S}$ proteasome by an AMPK-independent mechanism. FEBS Lett 582: 2650-2654.

8. Tartarin P, Guibert E, Touré A, Ouiste C, Leclerc J, et al. (2012) Inactivation of AMPK $\alpha 1$ induces asthenozoospermia and alters spermatozoa morphology. Endocrinology 153: 3468-3481.

9. Ceolotto G, Gallo A, Papparella I, Franco L, Murphy E, et al. (2007) Rosiglitazone reduces glucose-induced oxidative stress mediated by NAD(P)H oxidase via AMPK-dependent mechanism. Arterioscler Thromb Vasc Biol 27: 2627-2633.

10. Nguyen TM, Seigneurin F, Froment P, Combarnous Y, Blesbois E (2015) The 5'-AMP-Activated Protein Kinase (AMPK) is involved in the augmentation of antioxidant defenses in cryopreserved chicken sperm. PLoS One 10: e0134420.

11. Jeon SM, Chandel NS, Hay N (2012) AMPK regulates NADPH homeostasis to promote tumour cell survival during energy stress. Nature 485: 661665.

12. Viollet B, Guigas B, Sanz Garcia N, Leclerc J, Foretz M, et al. (2012) Cellular and molecular mechanisms of metformin: an overview. Clin Sci (Lond) 122: 253-270.

13. Fico A, Paglialunga F, Cigliano L, Abrescia P, Verde P, et al. (2004) Glucose-6-phosphate dehydrogenase plays a crucial role in protection from redox-stress-induced apoptosis. Cell Death Differ 11: 823-831.
ISSN: 2574-1241

DOI: 10.26717/BJSTR.2018.09.001825

Thi Mong Diep NGUYEN. Biomed J Sci \& Tech Res

(c) (P) This work is licensed under Creative

Submission Link: https://biomedres.us/submit-manuscript.php Commons Attribution 4.0 License

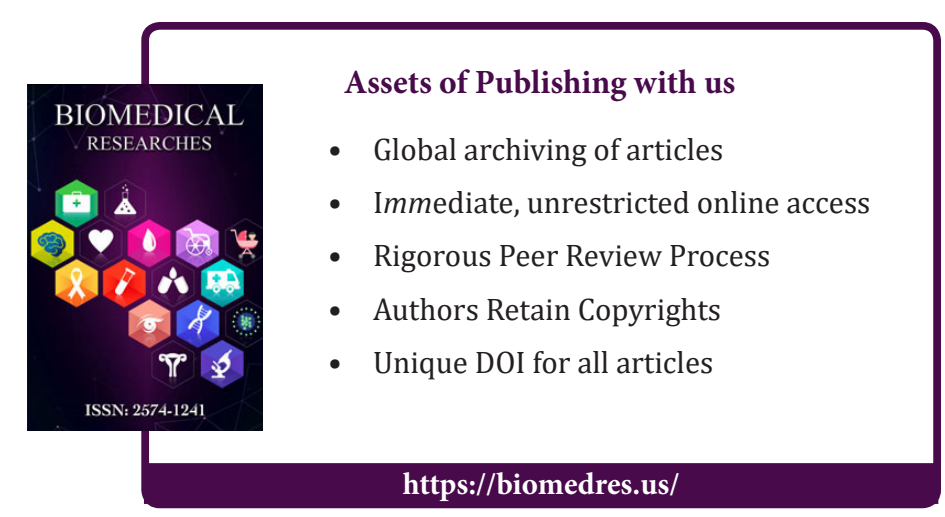

